\title{
FORMING OF INFORMATION CULTURE WITH TOOLS OF ELECTRONIC DIDACTIC MATERIALS
}

\author{
Nadezhda Almazova, Darina Barinova \& Oleg Ipatov
}
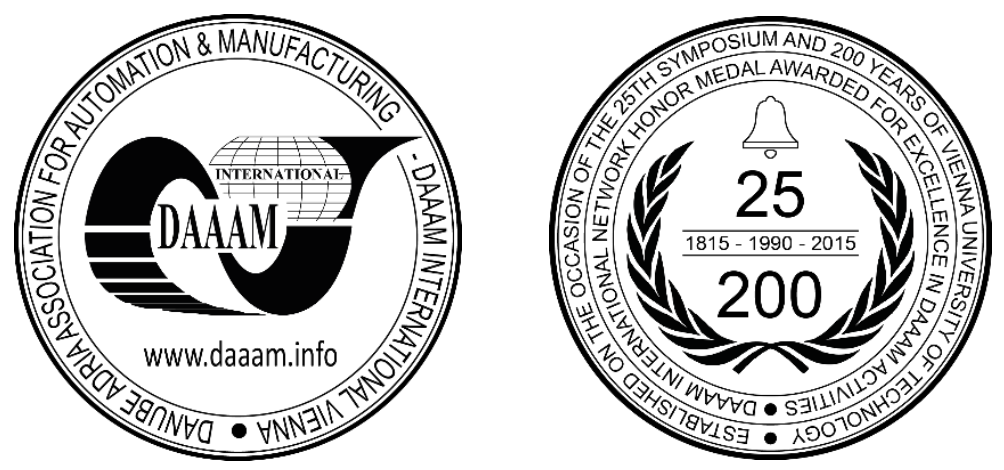

This Publication has to be referred as: Almazova, N[adezhda]; Barinova, D[arina] \& Ipatov, O[leg] (2018). Forming of Information Culture With Tools of Electronic Didactic Materials, Proceedings of the 29th DAAAM International Symposium, pp.0587-0593, B. Katalinic (Ed.), Published by DAAAM International, ISBN 978-3-902734-20-4, ISSN 1726-9679, Vienna, Austria

DOI: $10.2507 / 29$ th.daaam.proceedings.085

\begin{abstract}
The article covers the necessity of forming information culture of the students with the use of demonstrated technology. The information culture should be viewed as the achieved level of organization of information processes, the degree of satisfaction of people in information communication, the level of efficiency in the creation, collection, storage, processing, transmission, presentation and use of information that provides a holistic view of the world, anticipating the consequences of decisions. The structural-content characteristic of the information culture is determined, including the concepts of information literacy, information competence, information reflection, information value-semantic component and information cultural component. Due to the experiment results the application of technology of the electronic didactic materials integration can guarantee solid professional knowledge, skills and abilities to the students. Such personal qualities as the desire for creativity, responsibility for the task performed, the ability to organize own educational and cognitive activities and personal initiative are successfully formed in the process of performing tasks using the certain technology. The results of testing, questioning, observation and other methods of assessing students' progress have confirmed that the proposed technology for integrating the electronic didactic materials into the learning process provides the formation of all components of the information culture.
\end{abstract}

Keywords: information technologies; information culture; computer training tools; computerization; electronic didactic materials

\section{Introduction}

Nowadays the training of modern highly professional specialists in the humanitarian field demands integration of information technologies (IT) in the teaching and educational process in order to create such skills as: independently finding and analyzing new information, mastering new knowledge and independently searching for solutions of the complex professional problems. In this regard, the forming of the information culture (IC) of students becomes essential. Integration of information technologies in the training process influences not only the competence of the student in the field of information technologies, but above all the professional sphere of activity. We can note that the training of humanitarian specialists based on using information technologies will be improved if the following conditions are fulfilled: 
- a significant increase of the level of professional and general humanitarian cooperation between the teachers and the students due to the possibility of organising joint projects, including telecommunication;

- the expanding the capabilities of traditional libraries and university laboratories through access to electronic libraries and virtual laboratories, to scientific, educational and other cultural and socially significant Internet resources;

- increasing the effectiveness of independent work of students with both the traditional and electronic resources thanks to developed systems of self-monitoring and support of feedback from the teachers.

The application of information technologies can make the learning process modern and interesting, and also provide maximum support in mastering the humanities disciplines.

This paper proposes the new method of formation the IC with the means of electronic didactic materials. The proposed technology for integrating the electronic didactic materials into the learning process provides the formation of all components of the information culture and is proved by the experiment. The formation of the experiment expected the introduction of the electronic materials on semiotics to the educational process for the students of linguistic specialties in the technical university. To assess the effectiveness of the experiment, the level of the formation of the IC components before and after the experiment was diagnosed. The results of the experiment are demonstrated.

\section{Information culture}

The information culture should be viewed as the achieved level of organization of information processes, the degree of satisfaction of people in information communication, the level of efficiency in the creation, collection, storage, processing, transmission, presentation and use of information that provides a holistic view of the world, anticipating the consequences of decisions.

The methodologists face the task of developing pedagogical technologies that allow not only to use computer training tools, but also to form the the information culture of students.

According to many publications on this subject, it is possible to single out the components of the information culture as the basis for determining the very concept of "information culture". It allows to identify the parameters for diagnosing the formation of an information culture for a future specialist, and also the benchmarks that determine the goals, objectives, content and effectiveness of educational activities. The components of the information culture are:

- information (computer) literacy;

- information competence;

- information value-semantic component;

- information reflection;

- information cultural component [1].

The formation process of these components occurs during the productive educational and cognitive activity. Thus, the new teaching methods including modern information technologies should be involved together with the traditional activities in the class. In addition, a subject-subject, partnership relationship should be formed between the teacher and the students. Teachers act as managers and consultants for the projects and the research work.

\subsection{Information (computer) literacy}

Informational (computer) literacy can be manifested in the horizon, erudition, awareness of various phenomena of computerization and informatization, both from the point of view of scientific knowledge, and from the point of view of practical experience. An information literate person should be able to:

- determine the size of his information needs and requests;

- rationally and effectively obtain access to the necessary information;

- critically assess the level of information received and resources;

- $\quad$ introduce the selected information into the information base;

- effectively use information in accordance with the objectives;

- understand the economic, legal and social aspects of the use information, comply with ethical and legal norms in accessing and using information.

\subsection{Information competence}

The essence of competence is that it is a product of learning, and not tied to any particular discipline. At the same time, competence is not a direct result of training, but rather a consequence of the learner's self-development, his both professional and personal growth, the generalization of a variety of experiences.

We offer to understand, under the "information competence", first of all, the ability of the person in the information society to provide: free access to information; effective use of knowledge, skills to solve the tasks facing the person on the basis of computer literacy through efficiency, constructiveness of information activities (external and internal). 


\subsection{Information value-semantic component}

From our point of view, within the framework of humanitarian disciplines, it is necessary to form a value-semantic component of the personal information culture. The purposeful activity of teachers in establishing successive links between the course of the subject and information technology influences the motivation of the students, improves the cognitive interest in studying the subject, and the quality of their knowledge and skills.

So, the value-semantic component of the information culture can be defined as a system of personally significant and personally valuable aspirations, ideals, beliefs, views, positions in the process of acquiring knowledge in the field of information processes and relations [2]. Motivational and semantic structures of the personality actualize the formation and development of information competencies.

Therefore, professional thinking, analytical and communicative abilities, various behavioral models of using information and communication tools for solving different classes of professional tasks are formed. So it increases the efficiency of teaching, professional activity, labour productivity and creativity. It is obvious that the value-semantic component of the person's information culture influences the formation of literacy and competence, the development of reflection and also information cultural component. Also one of the main targets for the teacher is the creation of a positive motivation for learning, since lack of motivation prevents the emergence of the profound personal meaning in obtaining a quality education.

\subsection{Information reflection}

The next component of the information culture is information reflection. The creation of the new forms of education is undoubtedly connected with the tasks of purposeful formation of reflection. The problem of determining the conditions for the formation of reflection in educational activity becomes nowadays the subject of the study, and the development of means for its formation brings a practical possibility of managing the development of the subject and improving its activity. With regard to educational activity, modern researchers define reflection as the ability to realize one's own activity and, first of all, its result and the way it was achieved as the ability to analyze own means of cognition.

The formation of the capacity for reflection as an integrative personal education is determined, in our opinion, by the dynamic correlation of the level of awareness of all components of the performed activity (goals, conditions, methods, etc.) and the level of awareness of the means of its regulation. When studying the formation of the ability to reflect, it is necessary to diagnose the level of awareness of motivation, goals, conditions, methods of action, ways of regulation.

So, reflection is a person's tracking of the goals, process and results of his activity in the formation of an information culture, as well as an awareness of those internal changes that occur in himself as a changing personality, subject of activity and relationships. Human reflection encompasses all of its components: comprehension of one's own level of information literacy and competence, features of the value-semantic sphere.

The concept of reflection is closely related to the notion of critical thinking. According to research in this field, critical thinking is a natural way of interacting with information, the ability to think critically when examining it, to see different points of view, to analyze and draw conclusions [3].

\subsection{Principles of the independent work}

It is possible to single out the following principles during the independent work of students, which, in our opinion, influence the formation of reflection within the framework of the personality-oriented approach using information resources [4].

- The principle of independent activity determines the motivational aspect of the organization and conduct of the educational process. It is necessary to organize educational activities in such a way that students feel free in creative achievement of their goals.

- The principle of self-organization defines the operational and activity side of the learning process. This means that teaching any subject should be seen as learning to master its content. The success of students' own activity depends on the level of development of the student's cognitive abilities, the nature of the motivation of the training activity, its ability to self-regulation and self-organization.

- The principle of diverse forms of academic work implies that independent work, organized in different forms, is typical for students with different working capacities. The alternation of different forms of educational work prevents monotony in the activities of students, which is important for maintaining incentives for cognitive interest.

When working independently with electronic resources, these principles should be observed as follows. The principle of self-activity can be successfully realized, because students receive information directly from computer sources, and not from the teacher. Self-organization of the educational process can be realized due to the possibility of choosing the optimal mode of work for the student, corresponding to his individual tasks, using information technology. The principle of the diversity of the forms of academic work is simplified due to the control tasks in electronic form, the use of hypertext and multimedia technologies and the Internet. 


\subsection{Information cultural component}

It is obvious that the traditional educational model is not able to create conditions for the modern cultural process, in which the formation of the personality involves not only entering the culture, but also the production of its values. Creativity in this case must be immanent in education, and not an episodic activity. That is why there is a need to create new organizational forms of education, including, with the use of new information technologies.

Creativity as an embodiment of culture has many facets: from the creation of their own theories to culture; from mastering knowledge, skills and skills to culturally creative and cultural creation, to the implementation of creative projects. The teacher needs to achieve an understanding that the student is the co-creator of the relationship, communication, activity [5].

As mentioned above, the teacher's task is to organize the independent creative activity of students. In the classroom, the teacher should demonstrate the techniques of working with electronic resources, create a level of motivation sufficient for the successful completion of tasks and tests, and the formation of information cultural component of the information culture.

The logistics of the educational process should be sufficient to solve various problems effectively. In addition to the formation of knowledge, general skills and skills in a specific subject area, we, as part of the study, are concentrating on the creation of the IC of students. As a result, the electronic didactic materials were created and involved into the educational process [6].

\section{Electronic didactic materials}

By electronic didactic materials (EDM) we mean an interactive program-methodical resource based on the principles of modularity with the use of hypertext and multimedia technologies. These materials provide students the opportunity to:

- $\quad$ navigate and select the necessary theoretical material, practical work and control tasks;

- receive assistance in the implementation of practical tasks;

- $\quad$ conduct self-control on the material examined;

- implement the information retrieval activity of the student when referring to external sources [7].

\section{Experiment}

In total, 158 people took part in the experiment. In the control groups (CG), the classes were conducted in accordance with the semiotics program for students of the specialty of theoretical and applied linguistics of St.-Petersburg Baltic State Technical University "Voenmeh" (St.-Petersburg, Russia). In the experimental groups (EG) the students used the electronic resources. The formation of the experiment expected the introduction of the electronic materials on semiotics to the educational process for the students of linguistic specialties in the technical university. To assess the effectiveness of the experiment, the level of the formation of the IC components before and after the experiment was diagnosed. Measurements were carried out both in the ordinal scale (the scale of ranks), and in the relationship scale, and in the subsequent processing of the results were transformed into a single grade scale, with a gradation of 3 (high, medium, low) for each parameter. A preliminary assessment of the level of information culture of students-linguists was carried out on the basis of the developed methodology, including the diagnosis of the formation of the basic IC components: information literacy (K1), competence (K2), reflection (K3), value-semantic component (K4) and cultural component (K5) on the basis of terminology testing, psychological tests, questionnaires and interviews.

Analysis of the data of the preliminary study showed that the level of information culture among the students of EG and KG was not high enough. The results for each component with a high, medium and low division are demonstrated in Figure 1.

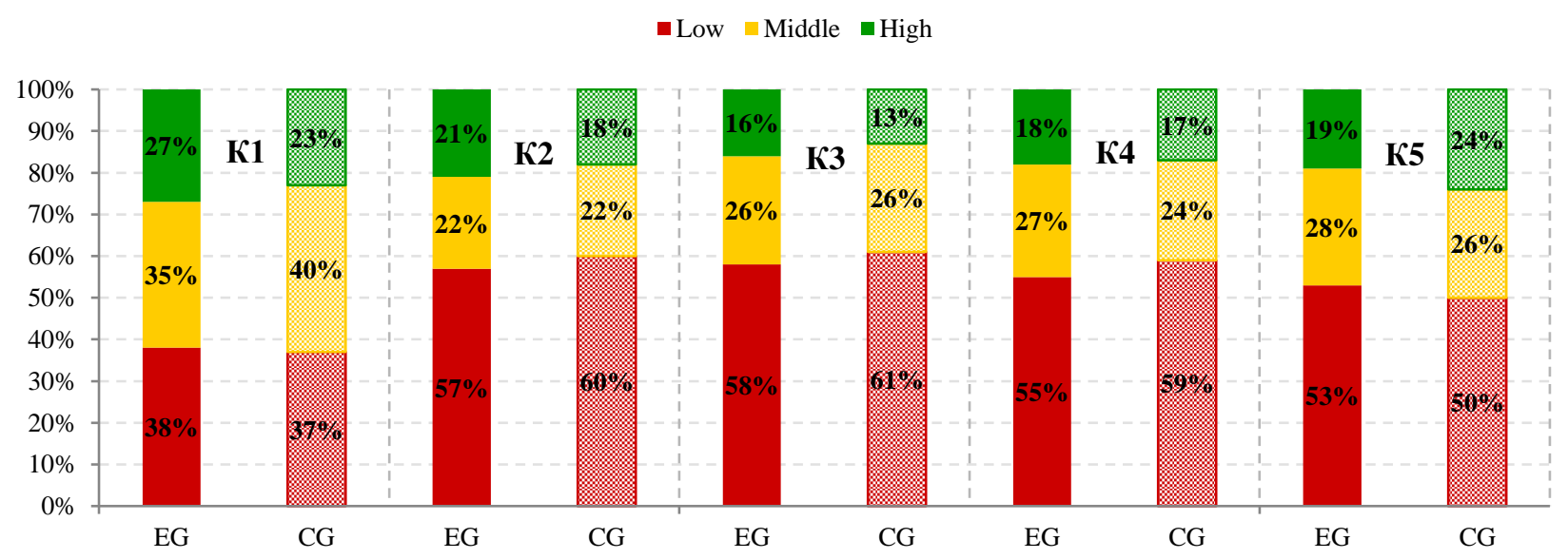

Fig. 1. Formation of the IC components (pre-experimental section) 


\subsection{Forming of IC components}

Such components of the IC as the information (computer) literacy, information competence, the information valuesemantic component and the information cultural component were formed when doing the tasks concerning the individual semiotic object. Such tasks involved the personal information requests and consisted of a number of aspects, when a lot of time was devoted to the search, study and presentation of information, analysis of scientific publications and data on the selected topics. They also expected the creative independent work including independently performed search tasks with the use of electronic resources [8].

The access to the necessary information on semiotics was carried out by students at the expense of the structured material and vocabulary, and also due to Internet-links to useful sources of discipline. Using of navigation systems, multimedia and hypermedia technologies, text and graphic editors, working in HTML format of the EDM also provided the basic components of the IC.

For successful work, students are encouraged to use various blocks of the EDM. For optimal preparation for the semiotic analysis, students performed test tasks after each of the topics covered and also used blocks of reference and additional materials: video files, reference materials, tips and the dictionary.

Independent work during these tasks provided the ability to manage learning activities, during which the student independently determines the goals of the training, its content and strategy, and also chooses general methods and methods of self-education and gives an objective self-assessment of the fulfilled work.

In this case, the student realizes responsibility for the educational process, the principle of cooperation, constructive and creative activity, reflective self-esteem and shows business activity $[9,10]$. Due to self-preparation on the above topics and tasks, the cognitive activity of the student, incentives for ensuring a full discussion with the teacher and other students, effective ways of managing independent learning activity, self-training mechanisms were perfected, which, in our opinion, contributed to the formation of cultural creativity, as one of the necessary components of the information culture of the learner's personality. Thus, the search and processing of information for the purpose of analysing the semiotic object, which was chosen by the students themselves, allowed to form one more component of the information culture the value-semantic one.

\subsection{Methodology of information reflections formation}

As we have mentioned above, the next component of the IC - information reflection - is determined by the dynamic correlation of the level of all components of the performed activity and the level of awareness of their regulation. On these basis, we refined the methodology for the formation of reflection using the EDM (Table 1).

\begin{tabular}{|c|c|}
\hline Formation conditions of reflection & Method of formation of reflection \\
\hline $\begin{array}{l}\text { Formation of motivational readiness for the development } \\
\text { of reflective abilities. }\end{array}$ & $\begin{array}{l}\text { Developing the student's conscious desire to focus on the } \\
\text { learning process through questionnaires, surveys, feedback } \\
\text { from the teacher. }\end{array}$ \\
\hline $\begin{array}{l}\text { Students' knowledge of the structure and content of } \\
\text { training activities, the availability of ideas about } \\
\text { effective ways of its regulation. }\end{array}$ & $\begin{array}{l}\text { Acquaintance with the forthcoming course, its goals and } \\
\text { tasks. }\end{array}$ \\
\hline $\begin{array}{l}\text { Overcoming the absorption of one's own activity, } \\
\text { providing an analysis position for performing additional } \\
\text { thought actions. }\end{array}$ & $\begin{array}{l}\text { Dialogue mode of communication, creative tasks, } \\
\text { placement of the trainee in the place of training, inclusion } \\
\text { of students in the analysis of their own methods of activity, } \\
\text { providing students with the choice of the desired module or } \\
\text { topic. The breakdown of the theoretical module into goals, } \\
\text { objectives and main topics of the lecture. }\end{array}$ \\
\hline Training of intellectual self-regulation. & $\begin{array}{l}\text { Activation of training activities through the development } \\
\text { of self-control methods, tests for self-examination, the } \\
\text { development of self-monitoring processes by including in } \\
\text { video materials educational materials from student's } \\
\text { studies. }\end{array}$ \\
\hline Development of the creative component of thinking. & $\begin{array}{l}\text { Stimulation of independent formulation of scientific } \\
\text { problems and creative activity. Organization of seminars in } \\
\text { the form of discussions. }\end{array}$ \\
\hline Developing content of forms of control. & $\begin{array}{l}\text { Ability for self-test. Organization of the exam as a creative } \\
\text { task. }\end{array}$ \\
\hline Subject-subject interaction and living communication. & Group work, discussions on selected topics. \\
\hline
\end{tabular}

Table 1. The ratio of conditions and methods of forming information reflection 


\subsection{Activities and tools}

For the post-experimental diagnostics we have determined the activities and tools which allow to estimate the degree of IC formation, they were:

- the results of terminology tests during the whole semester;

- the number of active students in the group during all classes;

- the number of initiatives in the classroom (participating in the discussion, arguments, comments on the issues addressed in the classroom);

- the number of initiatives that are significant in the discipline under study, according to the subject;

- the results of the final test;

- the results of the creative final work.

On the basis of the allocated empirical referents, an assessment was made of the formation of the components of the information culture on the basis of the criteria that form them. The results are shown in Figure 2.

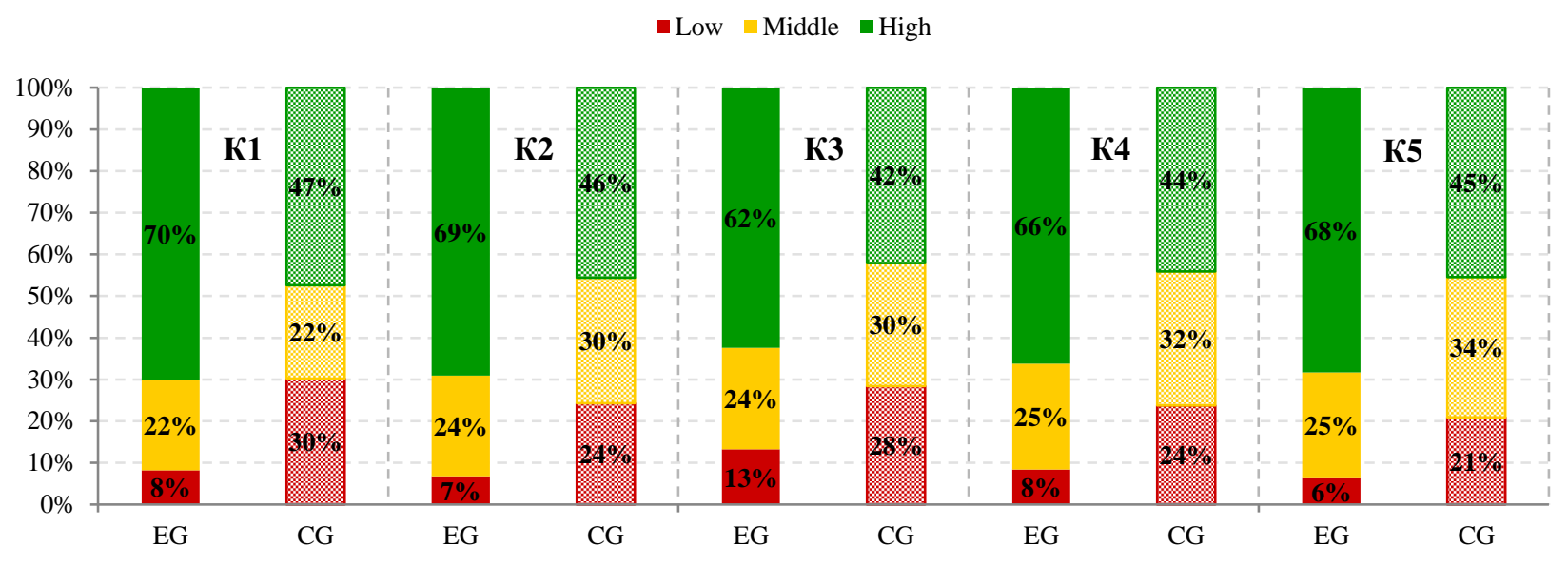

Fig. 2. Formation of the IC components (postexperimental section).

\section{Conclusion}

The statistical data obtained influences the optimization of the educational and learning processes. The application of technology of the electronic didactic materials integration can guarantee solid professional knowledge, skills and abilities to the students, as is convincingly evidenced by the data of postexperimental diagnostics. Such personal qualities as the desire for creativity, responsibility for the task performed, the ability to organize your own educational and cognitive activities and personal initiative are successfully formed in the process of performing tasks using computer technology. These qualities need to be formed during the learning process in different fields.

As we see, the results of testing, questioning, observation and other methods of assessing students' progress have confirmed our hypothesis that the proposed technology for integrating the electronic didactic materials into the learning process provides the formation of all components of the information culture. Electronic materials served to intensify immersion students in the work with information, contributed to the conscious formation and development of skills in working with information from students, provided an opportunity to consolidate the acquired skills in direct educational activities and as a result, formed all the components of the IC. Thus such components of the IC as the information (computer) literacy, information competence, the information value-semantic component and the information cultural component were successfully formed.

Such electronic didactic materials can be created in different fields of science to provide the opportunity to develop IC for students in order to create such skills as: independently finding and analyzing new information, mastering new knowledge and independently searching for solutions of the complex professional problems. Our future work can be devoted to implementing didactic materials based on the same principles for other disciplines.

\section{References}

[1] Fomin, V. (2009). Information culture in the training of a modern specialist, Izvestiya Samara, Vol. 11, No. 4 (30), 2009, pp. 69-72

[2] Popova, N.V., Almazova, N.I., Khalyapina, L.P., Tret'jakova, G.V. (2017). Intercollegiate telecommunication project as means of enhancing learner motivation in foreign language teaching Proceedings of the 15th international conference "E-society 2017" (pp.202-206) Hungary, Budapest, International Association for Development of the Information Society (IADIS) 
[3] Razinkina, E., Pankova, L., Trostinskaya, I., Pozdeeva, E., Evseeva, L., Tanova, A. (2018). Student satisfaction as an element of education quality monitoring in innovative higher education institution // E3S Web of Conferences, Volume 33, 03043 (2018). https://doi.org/10.1051/e3sconf/20183303043

[4] Gashkova, E., Berezovskaya, I., Shipunova, O. (2017) Models of self-identification in digital communication environments RPTSS 2017 International Conference on Research Paradigms Transformation in Social Sciences, The European Proceedings of Social \& Behavioural Sciences EpSBS, Vol. XXXV, $374-382$. doi:http://dx.doi.org/10.15405/epsbs.2018.02.44

[5] Nikiforova N. (2015) The Concept of Technology and the Russian Cultural Research Tradition Technology and Culture, John Hopkins University Press, Vol. 56, №1, pp. $184-203$

[6] Barinova D. (2017). Didactic aspects of integration technology of electronic resources into teaching semiotics, Teaching Methodology in Higher Education, Vol. 6. No 23, 2017, pp. 22-28. DOI: 10.18720/HUM/ISSN 22278591.23 .3

[7] Kogan, M.S., Khalyapina, L.P., Popova, N.V. (2017). Professionally-oriented content and language integrated learning (CLIL) course in higher education perspective // ICERI 2017 Proceedings: 10th International Conference of Education, Research and Innovation. 16th-18th November, Seville, SPAIN, pp. 1103-1112

[8] Zhigadlo, V.E., Odinokaya, M.A. (2017). Using the technology of educational podcasts for teaching Hindi in a technical university as a means of improving the quality of additional numeracy education. Language and Culture, 38, 207-226. doi: 10.17223/19996195/38/14

[9] Merriam S. (2013). Adult Learning: Linking Theory and Practice / Sharan B. Merriam, Laura L. Bierema. - JosseyBass, 2013., Pp. 320

[10] Yerofeyev S., Ipatov O., Markov S., Potekhin V., Sulerova A., Shkodyrev V. (2016). Adaptive Intelligent Manufacturing Control Systems, Proceedings of the 26th DAAAM International Symposium, pp.1016-1024, B. Katalinic (Ed.), Published by DAAAM International, ISBN 978-3-902734-07-5, ISSN 1726-9679, Vienna, Austria. 